\title{
A Quantitative Study of the Text of China's School National Unity Education Policy from the Perspective of Policy Tools
}

\author{
Wang Xuan ${ }^{1, *}$ \\ ${ }^{1}$ Research Center for Education of Northwest Ethnic Minorities, Northwest Normal University, Lanzhou, 730070, China \\ *Corresponding author.Email: waxua81@163.com
}

\begin{abstract} education policy tools in China are analyzed.

\section{INTRODUCTION}

In recent years, scholars have conducted preliminary research on the bilingual policy of ethnic minorities in China [1], the education policy of Tibetan classes in the mainland [2][3], and the macro-ethnic education policy [4][5] from the perspective of policy tools. The study mainly explores the choice and use of policy tools in the field of ethnic education in China. Since the 1980s, the state has issued a series of policies for national unity education in schools, which is of great significance for the development of national unity education in schools in China. However, in the process of policy implementation, it is necessary to conduct in-depth analysis on the selection and use of corresponding policy tools.
\end{abstract}

Through the collection, collation, coding and quantitative analysis of the national unity education policy documents at the national level, a two-dimensional analysis framework of school unity education policy tools is constructed, and on this basis, the distribution characteristics, functions and problems of school unity

Keywords: policy tools; national unity education; quantitative analysis

\section{BACKGROUND}

Policy tools refer to the path and mechanism by which the government translates its substantive goals into concrete actions. [6] As a bridge between policy goals and results, the correct selection and design of policy tools is the basic guarantee for the smooth realization of policy goals. [7] As a public policy, the school ethnic unity education policy is based on paying attention to and solving the problem of ethnic unity education. This study attempts to draw on the theory of policy tools and combine the basic elements of school ethnic unity education to construct a twodimensional analysis framework with the school ethnic unity education policy tool as the horizontal and its basic elements as the vertical. Application status and implementation of basic elements.

\subsection{Horizontal Dimension: Educational Policy Tools for National Unity in Schools}

Lorraine McDonnell and Richard Elmore [8] divided policy tools into four types: command tools, incentive tools, capacity building tools and system change tools; Anne Schneider and Ingra Helen Ingram [9] divided policy tools into authoritative tools, incentive tools, capacity-building tools, symbolic and persuasive tools, and learning tools. Combining Macdonald's and Amore's and Schneider's and Ingram's classification criteria, this study divides government's policy tools for promoting national unity education in schools into command tools, incentive tools, capacity building tools, symbol and persuasive tools and systems 5 types of change tools.

\subsection{Vertical Dimension: Basic Elements of School National Unity Education}

This study divides the basic elements of national unity education in schools into target requirements, education methods, educational fields, educational significance, educational content, teacher allocation, curriculum materials, organizational management, evaluation and reflection, and comprehensive promotion of 10 elements. By establishing the types of policy tools and extracting the basic elements of school ethnic unity education, a verticalhorizontal two-dimensional analysis framework for school ethnic unity education is constructed. On this basis, the existing text of the policy of national unity education in schools at the national level is used as an analysis object to explore the basic structure of the policy tools of school national unity education in China, and to clarify the degree of attention to the basic elements of school national unity education. 


\section{METHODS}

\subsection{Data source}

The text of the national unity education policy of the school in this study was mainly retrieved through the Peking University magic weapon (http://www.pkulaw.cn/). Searched in the magic weapon of Peking University under the title of "Education for National Unity", and obtained a total of 10 relevant policy texts.

\subsection{Quantitative Analysis of the Text of the Policy of National Unity Education in Schools}

The analysis unit of this study is the 10 policy texts included in the analysis. The analysis categories are the policy tool dimension and the basic element dimension of school ethnic unity education in the above two-dimensional framework. By manually coding and categorizing the analysis units included in the policy text in accordance with "Policy Number-Specific Clauses / Chapters", a policy text content analysis unit coding table is formed (see Table 1). For example: $3-1-1-3$ indicates the first article in the third policy document "Implementation Opinions on the Pilot Implementation of Ethnic Common Knowledge Education in Primary and Secondary Schools in Some Provinces and Municipalities" The three paragraphs "enhancing national unity and safeguarding the motherland's unification are listed as important contents of patriotic education in schools." After the coding is completed, a statistical analysis is made of the policy tools and basic elements used

Table 1 Content analysis unit coding table of school ethnic unity education policy text (partly)

\begin{tabular}{|c|c|c|c|}
\hline NO & Policy text name & Content analysis unit & Coding \\
\hline 1 & $\begin{array}{l}\text { Notice on Paying Attention to the } \\
\text { Party's Ethnic Policies and } \\
\text { Strengthening the Education of } \\
\text { Ethnic Unity in Schools at All } \\
\text { Levels }\end{array}$ & $\begin{array}{l}\text { Foreword: It is necessary to regularly and } \\
\text { actively carry out the party's ethnic policy } \\
\text { and positive education to strengthen } \\
\text { national unity among students at all levels } \\
\text { of school. }\end{array}$ & $1-0-5$ \\
\hline \multirow[b]{2}{*}{3} & \multirow[b]{2}{*}{$\begin{array}{l}\text { Opinions on the implementation } \\
\text { of pilot projects on common } \\
\text { sense education in primary and } \\
\text { secondary schools in some } \\
\text { provinces and cities }\end{array}$} & $\begin{array}{l}\text { I. Raising awareness and strengthening } \\
\text { leadership } \\
\text { (1) ... "It is important to strengthen the } \\
\text { unity of the nation and safeguard the unity } \\
\text { of the motherland as an important part of } \\
\text { school patriotism education." ... }\end{array}$ & $3-1-1-3$ \\
\hline & & $\begin{array}{l}\text { (4) To carry out national common sense } \\
\text { and national unity education activities } \\
\text { among primary and middle school } \\
\text { students, we must pay close attention to the } \\
\text { integration of teaching in various subjects } \\
\text { and patriotic education activities, pay } \\
\text { attention to the psychological } \\
\text { characteristics suitable for primary and } \\
\text { middle school students, and make them } \\
\text { lively, diverse, and entertaining. }\end{array}$ & $3-3-4$ \\
\hline ... & $\ldots .$. & $\ldots .$. & $\ldots$ \\
\hline 10 & 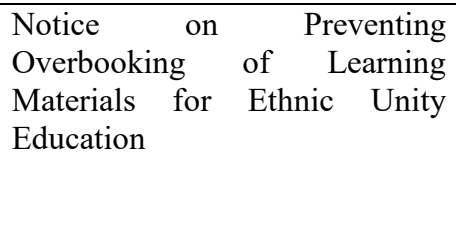 & $\begin{array}{l}\text { Foreword: The systematic implementation } \\
\text { of national unity education activities in } \\
\text { primary and secondary schools is an } \\
\text { important part of strengthening patriotism } \\
\text { and comprehensively implementing } \\
\text { quality education. }\end{array}$ & 10-0-1 \\
\hline
\end{tabular}




\section{RESULTS}

\subsection{Distribution Characteristics of Policy Tools for National Unity Education in Chinese Schools}

In the 10 policy texts, all five policy tools are applied; in the dimension of policy tools, the symbols and persuasion tools and command tools with the most applications and the highest proportion are used; the systems with the least applications and the lowest proportion are the tools for system change. In terms of the basic element dimension of school national unity education, all 10 elements are involved; in the basic element dimension, the most applied and highest proportion are the target required elements, and the least applied and lowest proportion are the comprehensive promotion elements.

\subsection{Dimensional Analysis of Policy Tools for National Unity Education in Schools}

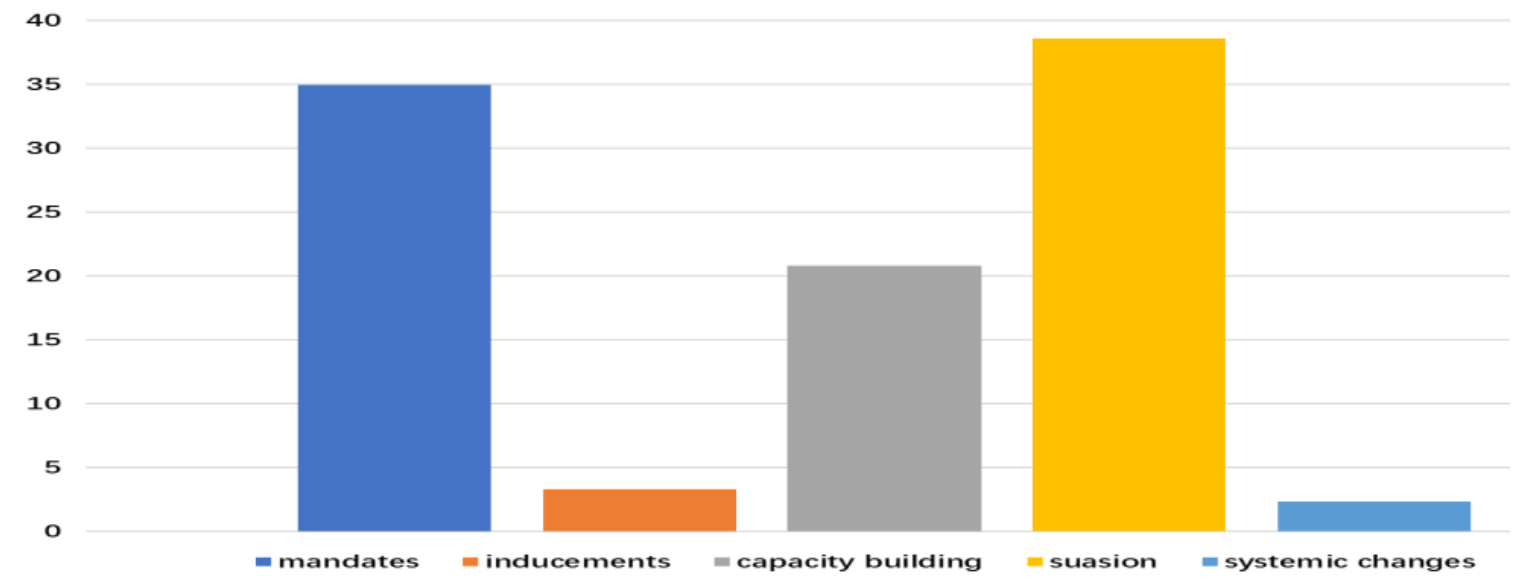

Figure 1 Frequency ratio of educational policy tools for ethnic unity in schools

From the two-dimensional distribution of the policy tools for school ethnic unity education with the frequency scale of the policy tools (Figure 1), we can see that of all the 10point policy documents, the symbol and persuasion tools were used the most, 117 times were used, accounting for $38.61 \%$; followed by the command tool, which was used 106 times, accounting for $34.98 \%$, which accounted for $74 \%$, which is the most frequently used policy tool for school ethnic unity education in our country; the capacity building tool was used 62 times, The ratio is $20.79 \%$; the incentive tool and the system change tool are used 10 times and 7 times respectively, and the ratio of the two is only $5.6 \%$.

\subsection{Dimensional Analysis of the Basic Elements of National Unity Education in Schools}

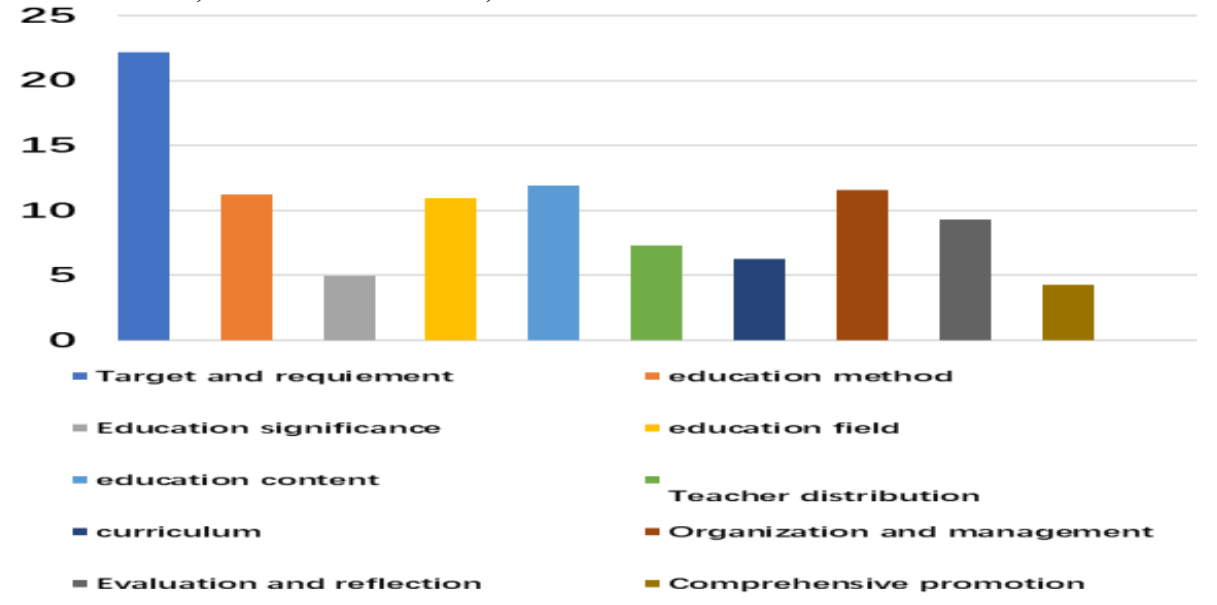

Figure 2 Frequency ratio of basic elements of national unity education in schools 
From the research results, we can see that the target requirements in 10 policy documents appear 77 times in total, accounting for $22.19 \%$, accounting for school unity education. Than the highest element. Secondly, there were 35 times in organizational management, accounting for $11.59 \%$; 36 times in educational content, accounting for $11.92 \% ; 34$ times in educational methods, accounting for $11.26 \%$; 33 times in educational fields, accounting for $10.93 \%$. In addition, evaluation and reflection (9.27\%), teacher allocation $(7.28 \%)$ and curriculum materials $(6.29 \%)$ accounted for a low proportion in school ethnic unity education activities; comprehensive promotion (4.30\%) accounted for the proportion of school ethnic unity education elements Too low.

\section{CONCLUSION}

\subsection{The command tool is used too frequently}

It can be seen from the results that the command tool is the most used tool by the government in the national unity education of schools in China. Mandatory policy tools provide instructions to policy executors in the form of coercion, force policy executors and policy targets to obey, and require policy target groups to take actions consistent with the requirements of policy makers. This shows that the government expects to achieve its basic goal of national unity education in schools in a low-cost, high-efficiency, rapid, and convenient way through its own authority, mandatory requirements, and implementation of responsibilities. China is a multi-ethnic country, and the differences between different provinces and regions are very large. The goal of the "one size fits all" command tool requires that the policy environment and the target group's differences in population be ignored, and the policy effect will be greatly reduced.

\subsection{Extensive use of symbolic and persuasive tools, and serious shortage of incentive and systematic change tools}

The study found that in the school's national unity education policy, symbolic and persuasive tools have been widely used in educational methods, educational fields, educational content, and evaluation and reflection, which shows that the government is more likely to expect encouragement, appeal, publicity, etc. Ways to guide the development of school ethnic unity education, strengthen the obedience of the educated, and form the long-term effect of school ethnic unity education.

The lack of incentive tools indicates that the state is lacking in providing differentiated feedback to target audiences in the process of promoting the implementation of national unity education in schools and weakens the effect of school national unity education. The sparse application of system change tools indicates that the state has less discretionary power and lower chances for different schools to choose policy tools, which is not conducive to obtaining lower school unity education experience.

\subsection{Unequal allocation of policy tools for the basic elements of school ethnic unity education}

In terms of the requirements for the school's national unity education, the central government mainly uses command tools to achieve it through hard rules; it reflects the state's resolute implementation of the national will and the spirit of the national policy formulated in the development process of school national unity education. Strong desire.

In terms of the education methods and educational significance of school ethnic unity education, the government mainly uses symbolic and persuasive policy tools, with a view to guiding, publicizing and other means to enable target groups to understand the significance of school ethnic unity education. Learn to apply different and diversified education methods to promote the education of national unity in different schools.

In terms of the educational field and educational content of the school's national unity education, it mainly configures command tools and symbolic and persuasive tools. The order tool stipulates the basic content and education field of school ethnic unity education, and the symbolic and persuasive tool guides the education method and education field through means such as calling and encouragement.

In terms of teacher allocation, organizational management, and curriculum materials, the development of national unity education in schools is mainly promoted through capacitybuilding tools. Teachers are the main focus of ensuring the long-term effects of national unity education in schools, and also the key to the capacity building of national unity education in schools. Curriculum and teaching materials are the main carrier of school national unity education knowledge transmission, which needs the state to promote the use of capacity-building tools; organizational management is carried out through capacity-building tools, indicating that the central government expects to strengthen different levels of education by strengthening the leadership and management of education administrative departments at all levels The organizational and management capabilities of the education administration department promote the development

In terms of evaluation and reflection, it mainly deploys symbolic and persuasive tools, and reflects on the achievements, problems, and challenges faced by the school's national unity education through persuasion and guidance; by encouraging and calling on different schools and teachers to pay attention to summing up experiences and teaching rules to improve teaching methods and explore new ways of education. In terms of comprehensive promotion, the allocation of various policy tools is very scarce, indicating that in the field of school ethnic unity education, the central government pays attention to the details of policy implementation. 


\section{ACKNOWLEDGMENT}

This work was supported by the National Social Science Foundation of China (19BMZ081)

\section{REFERENCES}

[1] Huang Cui, Zhao Peiqiang, Su Jun (2015). Quantitative Research on the Bilingual Education Policy of Ethnic Minorities in China Based on the Perspective of Policy Tools. Tsinghua University Education Research. 36 (5): 8895.

[2] Li Bo, Huang Zhongjing, Chen Jinlin(2008). An Analysis of the Implementation Tools of Ethnic Educational Policies in the Tibetan Classes in the Mainland of China. Journal of Tibet University, 23 (3): 106-111.

[3] Chen Qiaomei, Zhang Shiya(2016). Study on the effectiveness and policy tools of running schools in Tibetan areas —-Based on the analysis of " $9+3$ " in Tibetan classes (schools) in the mainland and Sichuan Tibetan areas. Ethnic Education Research, 27 (5): 24-30.

[4] Fu Songmao(2011). Development of Policy Tools for Ethnic Education in China. Fudan Education Forum, 9 (5) 14-17.

[5] Che Feng(2017). The Evolution and Prospects of China's Ethnic Education Policy-A Quantitative Analysis Based on the Text of the Policy. Journal of Southwest University for Nationalities, (12): 223-228.

[6] Zhang Chengfu, Dang Xiuyun(2001). Public Management Science. Beijing, Renmin University of China Press, pp 61-62.

[7] Yang Daifu(2016). Research on the Choice of Policy Tools_Based on the Perspective of Rationality and Policy Networks. Beijing, China Social Sciences Press, pp $1-35$.

[8] Lorraine M. McDonnell and Richard F. Elmore (1987) 'Getting the Job Done: Alternative Policy Instruments.' Educational Evaluation and Policy Analysis, 9 (2): 133-152.

[9] Anne Schneider and Helen Ingram (1990) 'Behavioral Assumptions of Policy Tools.' Journal of Politics ,52 (2): 510-529. 